\title{
Radiation Boost
}

National Cancer Institute

\section{Source}

National Cancer Institute. Radiation Boost. NCI Thesaurus. Code C137812.

One or more extra radiation treatments targ eted at the tumor bed, given after the regular sessions of radiation are complete. 